\title{
A Referential-coding Explanation for Compatibility Effects of Physically Orthogonal Stimulus and Response Dimensions
}

\author{
Yvonne Lippa \\ Max-Planck-Institut für psychologische Forschung, München, Germany
}

\begin{abstract}
This study addresses the dependence of compatibility effects on responding hand with horizontally oriented stimuli and vertically oriented responses ( $\mathrm{H}-\mathrm{V}$ effect) and with vertically oriented stimuli and horizontally oriented responses ( $\mathrm{V}-\mathrm{H}$ effect) reported by Bauer and Miller (1982). Experiment 1 replicated the H-V effect. In Experiment 2, the subject was instructed to respond with the hand in line with the response keys. That eliminated the $\mathrm{H}-\mathrm{V}$ effect. In Experiment 3, the response board was placed to the left or right side of the subject, yielding a considerably reduced $\mathrm{H}-\mathrm{V}$ effect and a novel compatibility effect dependent on board location. In Experiment 4, the $\mathrm{V}-\mathrm{H}$ effect was produced when the subject was required to respond with the hand in line with the response keys. With the hand rotated through $90^{\circ}$ in Experiment 5, the $\mathrm{V}-\mathrm{H}$ effect was eliminated, and a main effect of mapping was observed. The results challenge Bauer and Miller's movement-preference hypothesis and support a referential-coding hypothesis proposed by the author. This assumes that response positions are coded in reference to hand posture, so that physically orthogonal stimulus and response dimensions can overlap with respect to their mental representations. The applicability of this hypothesis to other compatibility effects is demonstrated, and its significance for compatibility theories is briefly discussed.
\end{abstract}

According to Fitts and Seeger (1953), stimulus-response compatibility (SRC) means that the quality of a particular response to a particular stimulus, in terms of reaction time and errors, depends not on stimulus or response characteristics alone, but on their interrelation. For instance, if subjects respond to left and right stimuli by pressing a left and a right response key, respectively, faster responses and fewer errors are observed if the left

Requests for reprints should be sent to Yvonne Lippa, Max-Planck-Institut für psychologische Forschung, Leopoldstr. 24, D-80802 München, Germany. Email: lippa@mpipf-muenchen.mpg.de

I wish to thank Bernhard Hommel, Gisa Aschersleben, Wolfgang Prinz, Stephen Monsell, Claire Michaels, and two anonymous reviewers for helpful suggestions and comments on earlier versions of this article; Fiorello Banci and Karl-Heinz Honsberg for constructing the response device, as well as Heidi John and Jonathan Harrow for checking and improving the English. 
key is assigned to the left stimulus and the right key to the right stimulus than the converse.

Usually, SRC effects have been observed under experimental conditions similar to those described, in which stimulus and response dimensions have physical or semantic features in common (e.g. left-right stimulus positions and left-right responses). This similarity of stimulus and response dimensions, in so far as it is cognitively coded, is called the dimensional overlap of an $\mathrm{S}-\mathrm{R}$ ensemble. Most theories of $\mathrm{S}-\mathrm{R}$ compatibility rely on the dimensional overlap of $\mathrm{S}-\mathrm{R}$ sets. For instance, automatic activation accounts (De Jong, Liang, \& Lauber, 1994; Kornblum, Hasbroucq, \& Osman, 1990) assume that SRC effects occur because activated stimulus codes automatically prime congruent (i.e. spatially or semantically similar) response codes, which presupposes some kind of dimensional overlap. Likewise, translation accounts argue that the efficiency of $S-R$ translation critically depends on $S-R$ correspondence: Fewer and simpler translation rules are needed in the presence of dimensional overlap than in its absence (Hasbroucq, Guiard, \& Ottomani, 1990; Umiltà \& Nicoletti, 1992; Welford, 1976). Thus, apart from differences in explaining the underlying mechanisms, most theories assume that overlapping $\mathrm{S}-\mathrm{R}$ dimensions are a necessary precondition for SRC effects to occur.

Against this background, it is interesting to note that SRC effects have been observed with physically orthogonal stimulus and response dimensions-for example, with topbottom stimulus positions and left-right responses (Bauer \& Miller, 1982; Cotton, Tzeng, \& Hardyck, 1977, 1980; Ehrenstein, Schroeder-Heister, \& Heister, 1989; Làdavas, 1987; Làdavas \& Moscovitch, 1984; Michaels, 1989; Michaels \& Schilder, 1991; Weeks \& Proctor, 1990; Weeks, Proctor, \& Beyak, 1995). This raises the following theoretical problem. On the one hand, one might assume that physically orthogonal $\mathrm{S}-\mathrm{R}$ dimensions are cognitively coded orthogonally, too. If so, there would be no dimensional overlap between stimulus and response codes, and SRC effects with physically orthogonal S-R sets would have to be explained in some other way. In fact, prior accounts have attributed them to characteristics of the motor system (Bauer \& Miller, 1982), to the correspondence between the salient polar referents of the $\mathrm{S}-\mathrm{R}$ sets (Weeks et al., 1995), or to cerebral hemispheric processing (Cotton et al., 1977, 1980). On the other hand, one could assume that despite physical orthogonality, $\mathrm{S}-\mathrm{R}$ dimensions can overlap with respect to their mental representations. In this case, the effects could be easily accounted for by existing compatibility theories. But then the question is how non-orthogonal codes are derived from physically orthogonal dimensions.

The purpose of the present study is to give an answer to the latter question. A referential-coding hypothesis is presented which assumes that responses are coded in reference to hand posture and can therefore be cognitively represented non-orthogonally with respect to the stimulus dimension. Accordingly, most effects with physically orthogonal stimulus and response dimensions require no special explanation but can be interpreted within the same framework as the classic SRC effects.

In order to test the referential-coding hypothesis, the present study focuses on two SRC effects with orthogonal S-R dimensions that were first reported by Bauer and Miller (1982) and served as a starting point for many other studies: an SRC effect with horizontally oriented stimuli and vertically oriented responses (the $H-V$ effect) and an SRC effect with vertically oriented stimuli and horizontally oriented responses (the $V-H$ 
effect). The direction of these effects depends on the hand that is used. Although both effects will eventually be regarded as two variants of the same effect, they are first treated separately. The first three experiments address the $\mathrm{H}-\mathrm{V}$ effect; Experiments 4 and 5 focus on the $\mathrm{V}-\mathrm{H}$ effect.

\section{THE H-V EFFECT}

In Bauer and Miller's (1982) first experiment, subjects responded to an "X" presented to the left or right of a central fixation point by pressing a response key located behind (upper key) and in front of (lower key) a central home key with their left index finger or, in a different block, their right index finger. Apart from the hand, S-R mapping was varied: One-half of the subjects responded with the upper key to left stimuli and with the lower key to right stimuli (left-up/right-down mapping), whereas the other half were given the reversed mapping (left-down/right-up mapping). The results were rather surprising: With left-up/right-down mapping, a reaction-time advantage of $34 \mathrm{msec}$ was observed for the left compared to the right hand, whereas with left-down/rightup mapping there was an advantage of $84 \mathrm{msec}$ for the right compared to the left hand. In other words, different SRC effects appeared for left- and right-hand responses. In order to ensure that this $\mathrm{H}-\mathrm{V}$ effect is reliable and occurs under the experimental condition used here, it was first of all replicated in Experiment 1.

\section{EXPERIMENT 1}

\section{Method}

\section{Subjects}

Eleven female and five male subjects aged between 20 and 39 were paid to participate in the experiment. All claimed to be right-handed and all had normal or corrected-to-normal vision.

\section{Stimuli and Apparatus}

Stimulus presentation and data acquisition were controlled by a Rhotron VME system. The stimuli, standard upper-case "X"s $(0.3 \times 0.4 \mathrm{~cm})$ in black on a white background, were presented on an Atari SM124 monitor. They appeared with their centres $1.5 \mathrm{~cm}$ to the left or right of a central fixation asterisk. The viewing distance was approximately $60 \mathrm{~cm}$.

Responses were made on a horizontal $31 \times 31-\mathrm{cm}$ response board interfaced with the computer. Three square sensor keys were mounted on the board: a central home key $(2.5 \times 2.5 \mathrm{~cm})$ and two response keys $(3 \times 3 \mathrm{~cm})$ located $2.7 \mathrm{~cm}$ (edge-to-edge) in front of and behind the home key relative to the subject's body. These are referred to, from the subject's perspective, as the "lower" and "upper" key, respectively. 


\section{Procedure}

Subjects were seated at the table on which the monitor and the response board were located and were required to keep their sagittal midline in line with the response keys and the fixation point (see Figure 1). The response board was $3 \mathrm{~cm}$ above table height and close to the edge of the table.

Their task was to move the index finger from the home key to touch the upper or lower key in response to left or right stimuli. Half the subjects responded to a left stimulus with the upper key and to a right stimulus with the lower key, whereas the other half used the reverse mapping. The session was divided into two blocks of 90 trials consisting of 10 practice trials and 80 test trials (40 for each stimulus location). In one block of trials subjects used the left index finger, and in the other block the right index finger only. The order of hands was balanced across subjects.

Each trial began with a display of the English command "HOME KEY!" in the centre of the screen, until the subject touched the home key with the index finger of the responding hand. After $100 \mathrm{msec}$, a fixation asterisk was presented for $1 \mathrm{sec}$, followed by the stimulus displayed randomly to the left or right of the fixation asterisk. The stimulus was visible until the subject responded or $1 \mathrm{sec}$ had passed (missing trial). If subjects left the home key before stimulus presentation, the trial was restarted with the "HOME KEY" display. Auditory feedback (a beep) was given on error and missing trials $(0.6 \%)$, which were then repeated at random positions in the block.

\section{Results}

Mean reaction time ( $\mathrm{RT}$ ), that is, the time needed to leave the home key, mean movement time (MT), that is, the time from movement onset to engagement of the response key, and percentages of error were calculated as a function of stimulus and response location and responding hand (see Table 1$)$. Trials with RTs of less than $120 \mathrm{msec}(0.3 \%)$ were excluded
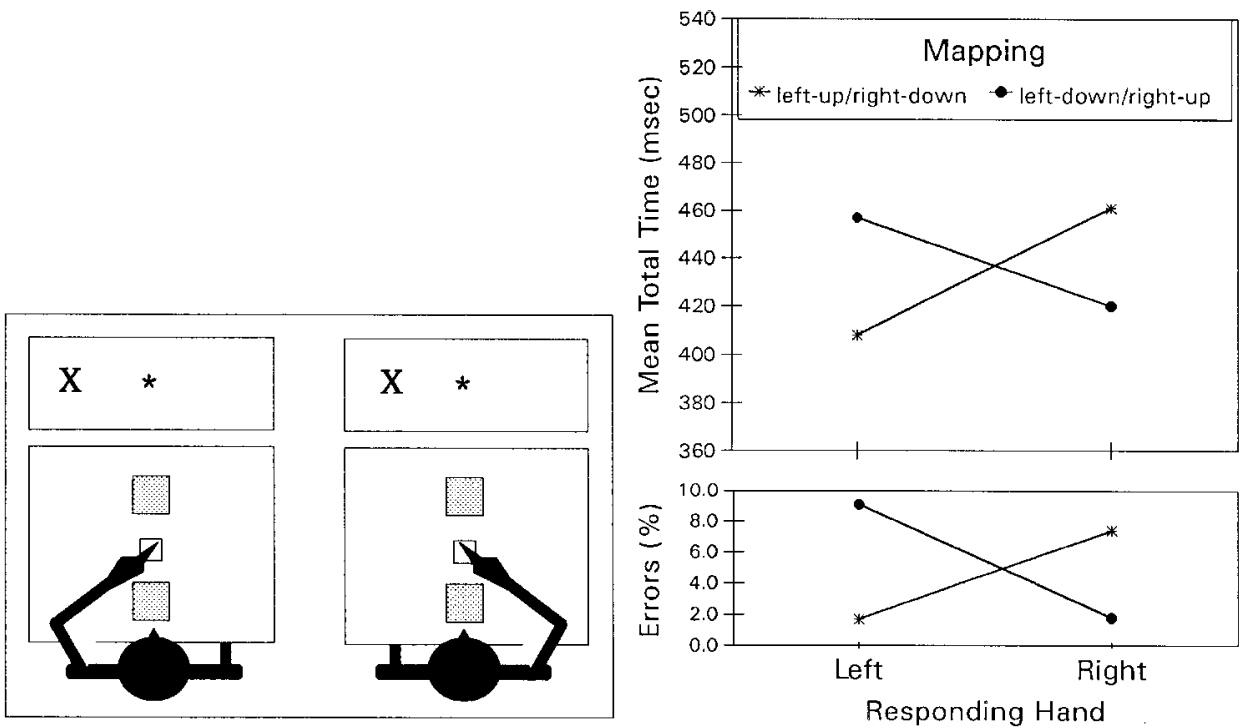

FIG. 1. Left panel: The hand posture of the left and the right hand, defining upper and lower response key positions as left and right. Right panel: The H-V effect in Experiment 1: total time and error rate as a function of mapping and responding hand. 
TABLE 1

Mean $\mathrm{RT}^{\mathrm{a}}, \mathrm{MT}^{\mathrm{a}}, \mathrm{TT}^{\mathrm{b}}$, and Error Data ${ }^{\mathrm{c}}$ for Experiment 1 as a Function of Responding Hand and Stimulus and Response Location

\begin{tabular}{|c|c|c|c|c|c|}
\hline \multirow{3}{*}{\multicolumn{2}{|c|}{ Response Location }} & \multirow{2}{*}{\multicolumn{2}{|c|}{$\frac{\text { Left Hand }}{\text { Stimulus Loca tion }}$}} & \multirow{2}{*}{\multicolumn{2}{|c|}{$\frac{\text { Right Hand }}{\text { Stimulus Location }}$}} \\
\hline & & & & & \\
\hline & & \multirow{2}{*}{$\frac{L e f t}{286}$} & \multirow{2}{*}{$\frac{\text { Right }}{331}$} & \multirow{2}{*}{$\frac{\text { Left }}{332}$} & \multirow{2}{*}{$\frac{\text { Right }}{303}$} \\
\hline $\mathrm{Up}$ & RT & & & & \\
\hline & $\mathrm{MT}$ & 131 & 136 & 130 & 127 \\
\hline & $\mathrm{TT}$ & 417 & 467 & 462 & 430 \\
\hline & Errors & 1.8 & 10.6 & 7.3 & 2.1 \\
\hline \multirow[t]{4}{*}{ Down } & RT & 314 & 288 & 295 & 350 \\
\hline & $\mathrm{MT}$ & 132 & 111 & 115 & 110 \\
\hline & $\mathrm{TT}$ & 446 & 399 & 410 & 460 \\
\hline & Errors & 7.6 & 1.5 & 1.4 & 7.5 \\
\hline
\end{tabular}

${ }^{\mathrm{a}}$ In msec; ${ }^{\mathrm{b}}$ total time in $\mathrm{msec} ;{ }^{\mathrm{c}}$ in $\%$.

from calculation. As the experimental situation allowed subjects to lift their fingers before the decision process or movement programming was complete, the relevant SRC effects may be distributed over RT and MT data. Therefore, total time (TT) - that is, the sum of RT and MT — was chosen as the primary measure, and separate analyses of RT and M T are reported only when their outcomes reveal relevant deviations from the main analysis. Analyses of variance (ANOVA) were conducted on the data, using the between-subject variable S-R mapping (left-up/right-down vs. left-down/right-up) and the within-subject variables response hand (left vs. right) and response location (upward vs. downward).

Total Times. The main effect of response location reached significance, $F(1,14)=$ $4.92, p<.05$, indicating that downward responses were faster $(429 \mathrm{msec})$ than upward responses $(444 \mathrm{msec})$. In addition, the relevant $\mathrm{Mapping} \times \mathrm{Hand}$ interaction was reliable, $F(1,14)=17.95, p<.01$. As Figure 1 shows, with the left hand left-up/right-down mapping was easier (408 $\mathrm{msec})$ than left-down/right-up mapping (457 $\mathrm{msec})$, whereas the preference was reversed with the right hand (461 vs. $420 \mathrm{msec}$ ).

Error Data. Only the Mapping $\times$ Hand interaction reached significance, $F(1,14)=$ $60.72, p<.001$ (see Figure 1). Left-hand responses were less error-prone with left-up / right-down mapping $(1.7 \%)$ than with left-down/right-up mapping $(9.1 \%)$; for righthand responses, the opposite pattern occurred (7.4 vs. $1.8 \%)$.

\section{Discussion}

In sum, the $\mathrm{H}-\mathrm{V}$ effect is replicable in total times as well as in error data. Unlike Bauer and Miller's study (1982, Exp. 1), the experiment yielded a cross-over interaction. That is, in addition to a difference in performance for the two hands across mappings, there was also a difference in performance for the two mappings across hands. This difference 
is due to a non-replicable overall reaction time advantage of $57 \mathrm{msec}$, found by Bauer and Miller for the left-up/right-down mapping. But there is no obvious explanation for it. Studies that report a main effect of orthogonal S-R mappings (e.g. Weeks \& Proctor, 1990 ) found only a superiority of up-right/down-left mapping.

The following sections present two different explanations for the $\mathrm{H}-\mathrm{V}$ effect: the movement-preference hypothesis proposed by Bauer and Miller (1982) and the referential-coding hypothesis proposed by the present author.

\section{The Movement-preference Hypothesis}

Bauer and Miller (1982) presumed that the structure of the motor system is responsible for the H-V effect. Specifically, they postulated that each movement in the H-V design is not a simple vertical movement, but actually a combination of two movements: The first (implicit) movement aims at the relative position of the stimulus (left vs. right), in the sense of responding tow ards the source of stimulation (Simon, 1969); the second (explicit) movement is the one required by instruction (upward vs. downward). Combining these two movements results either in a joint clockwise (e.g. first left, then upward) or in a joint counterclockwise (e.g. first left, then downward) movement. The H-V effect is explained by the assumption that clockwise movements, here caused by left-up/right-down mapping, are preferable for the left rather than the right hand, whereas counterclockwise movements, caused by left-down/right-up mapping, are preferable for the right rather than the left hand.

Bauer and Miller emphasized that these movement preferences are not fixed characteristics of each hand that occur independently of the experimental situation. In several pilot studies, they studied the speed of simple rotational movements for each hand, but they found no interactions between response hand and direction of rotation. Therefore, they concluded that "these preferences are manifest through combinations of implicit movements towards the stimulus and explicit movements towards the response key" (p. 367). Thus, when examining this hypothesis, it is important to maintain an experimental situation that evokes an implicit and an explicit movement. As long as this is present, the movement preferences should be effective, and a $\mathrm{H}-\mathrm{V}$ effect comparable to that observed in Experiment 1 should occur.

\section{The Referential-coding Hypothesis}

According to the referential-coding hypothesis proposed here, the $\mathrm{H}-\mathrm{V}$ effect is a simple spatial SRC effect. Specifically, it is assumed that physically "upward" and "downward" responses are coded as "left" and "right" responses and thus show dimensional overlap with the horizontally oriented stimulus set.

To understand this assumption, one has to re-examine the experimental situation that generates the $\mathrm{H}-\mathrm{V}$ effect. Subjects are instructed to respond with the index finger of one hand. As no special instruction is given about hand posture, subjects probably hold their hand at a comfortable angle (about $45-90^{\circ}$ ) to the line of the response keys (see Figure 1). If so, the hand (i.e. the intrinsic fingertip-to-wrist axis) might function as a reference 
point defining the position of the response keys ${ }^{1}$. That is, everything located to the left of the hand may be coded as LEFT and everything located to the right may be coded as RIGHT. In left-hand responding, the upper key would be coded as LEFT and the lower key as RIGHT. Conversely, with right-hand responding, the upper key would be coded as RIGHT and the lower key as LEFT.

If this is the case, the occurrence of the $\mathrm{H}-\mathrm{V}$ effect is no longer surprising. In left-hand responding, left-up/right-down mapping is compatible, because stimulus and coded response positions correspond, whereas the left-down/right-up mapping is incompatible, as stimulus and coded response positions do not correspond. With right-hand responses, the opposite coding is expected, so that left-down/right-up mapping is compatible and left-up/right-down mapping is incompatible.

In sum, the referential-coding hypothesis assumes that the hand functions as a leftright reference, so that upward and downward responses are coded as left and right, thus showing dimensional overlap with the stimulus set. Given standard hand postures, it follows that the mental representation of response direction depends on whether it is the left or the right hand that responds. In the case of left-hand responses, the upper key is coded as LEFT and the lower key as RIGHT, whereas the opposite coding is valid for righthand responses. This explains why the SRC effect depends on the responding hand. The following two experiments were carried out to test the referential-coding hypothesis against the movement-preference hypothesis.

\section{EXPERIMENT 2}

The referential-coding hypothesis explains the $\mathrm{H}-\mathrm{V}$ effect by proposing that the positioning of the hand at a $45-90^{\circ}$ angle to the line of the response keys causes the left-right coding of the response set. Therefore, it should be possible to eliminate the $\mathrm{H}-\mathrm{V}$ effect, or at least to reduce it considerably, by manipulating hand posture. This prediction was tested by instructing subjects to hold their responding hand and finger in line with the response keys, so that the keys were above and below the hand and, thus, should be coded as тор and воттом (see Figure 2). Regardless of the responding hand, left-up/rightdown mapping should now lead to similar performance to left-down/right-up mapping. In contrast, the movement-preference hypothesis predicts an $\mathrm{H}-\mathrm{V}$ effect comparable to the one obtained in Experiment 1, because the experimental situation still evokes the combination of an implicit and explicit movement, which is necessary for the movement preferences to be effective. So, with clockwise movements, better performance for the left hand is expected, and with counterclockwise movements, better performance for the right hand.

\footnotetext{
${ }^{1}$ Evidence for a reference function of the hand was found by Carpenter and Eisenberg (1978) in a haptic letter-judgement task. They showed that blindfolded subjects coded the orientation of a letter with respect to hand position. A letter presented at $0^{\circ}$ was identified fastest when the subject's hand and arm were perpendicular to the subject's frontal plane, whereas letters presented at $300^{\circ}$ were identified fastest with the forearm positioned at a $300^{\circ}$ angle to the subject's frontal plane.
} 

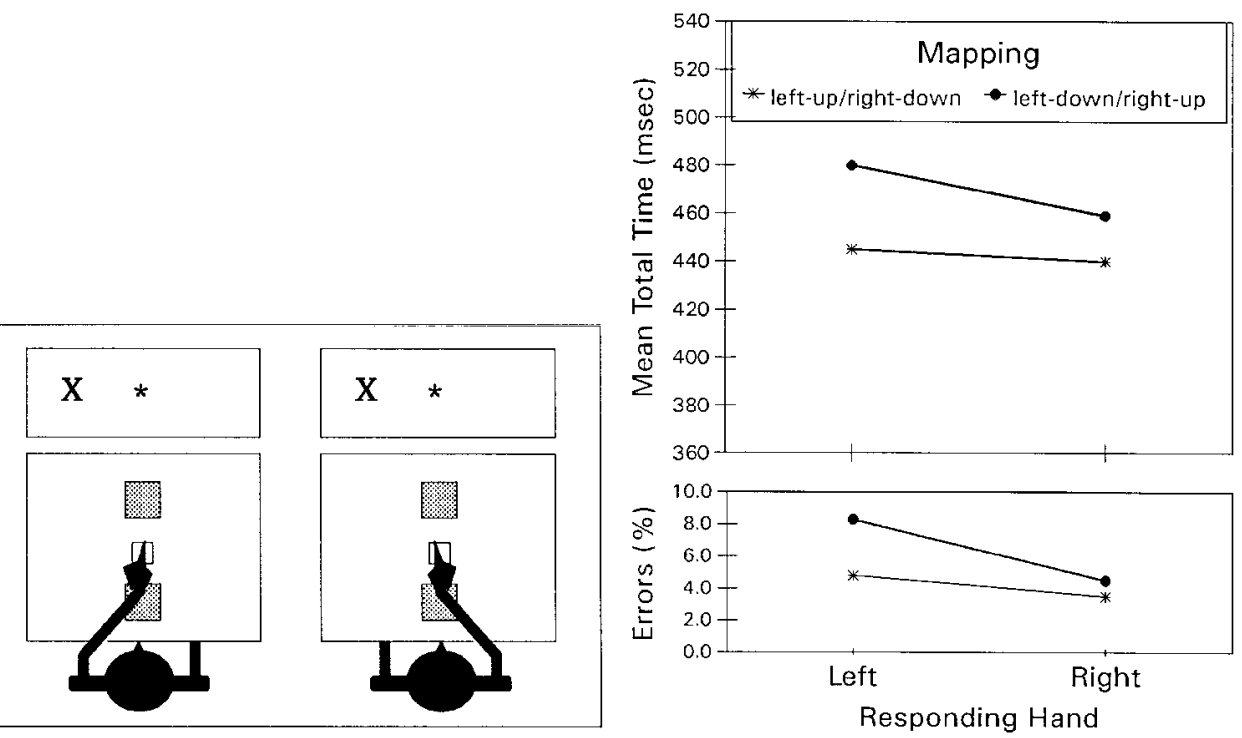

FIG. 2. Left panel: The hand posture required in Experiment 2 for left- and right-handed responses. Right panel: The absence of the $\mathrm{H}-\mathrm{V}$ effect in Experiment 2: total time and error rate as a function of mapping and responding hand.

\section{Method}

\section{Subjects}

Seven female and five male subjects (11 right-handed and 1 ambidextrous by self-report) aged between 16 and 38 were paid to participate in the experiment. They had normal or corrected-tonormal vision.

\section{Apparatus and Procedure}

These were the same as in Experiment 1, with the following exceptions: first, in addition to error and missing trials $(0.5 \%)$, trials with RTs less than $120 \mathrm{msec}(0.2 \%)$ were repeated at random positions in the block. Second, subjects were required to hold their responding hand in line with the response keys. To avoid uncomfortable hand postures, subjects were allowed to sit approximately $1 \mathrm{~m}$ away from the screen. The subject's sagittal mid-line and the hand were then in line with the response keys and the fixation asterisk.

\section{Results and Discussion}

RT, M T, and error data were treated and analysed as in Experiment 1, and their means are presented in Table 2 .

Total Times. Only the main effect of response location was reliable, $F(1,10)=6.23$, $p<.05$, indicating that downward responses were faster (446 $\mathrm{msec}$ ) than upward responses $(466 \mathrm{msec})$. The relevant Mapping $\times$ Hand interaction was far from being significant, $F<1$ (see Figure 2). 
TABLE 2

Mean $\mathrm{RT}^{\mathrm{a}}, \mathrm{MT}^{\mathrm{a}}, \mathrm{TT}^{\mathrm{b}}$, and Error Data ${ }^{\mathrm{c}}$ for Experiment 2 as a Function of Responding Hand and Stimulus and Response Location

\begin{tabular}{|c|c|c|c|c|c|}
\hline \multirow{3}{*}{\multicolumn{2}{|c|}{ Response Location }} & \multirow{2}{*}{\multicolumn{2}{|c|}{$\frac{\text { Left Hand }}{\text { Stimulus Loca tion }}$}} & \multirow{2}{*}{\multicolumn{2}{|c|}{$\frac{\text { Right Hand }}{\text { Stimulus Location }}$}} \\
\hline & & & & & \\
\hline & & \multirow{2}{*}{$\frac{L e f t}{345}$} & \multirow{2}{*}{$\frac{\text { Right }}{341}$} & \multirow{2}{*}{$\frac{L e f t}{341}$} & \multirow{2}{*}{$\frac{\text { Right }}{325}$} \\
\hline $\mathrm{Up}$ & RT & & & & \\
\hline & $\mathrm{MT}$ & 118 & 150 & 113 & 132 \\
\hline & $\mathrm{TT}$ & 463 & 491 & 454 & 457 \\
\hline & Errors & 5.3 & 12.1 & 5.0 & 6.5 \\
\hline \multirow[t]{4}{*}{ Down } & RT & 340 & 338 & 344 & 343 \\
\hline & $\mathrm{MT}$ & 129 & 89 & 117 & 82 \\
\hline & $\mathrm{TT}$ & 469 & 427 & 461 & 425 \\
\hline & Errors & 4.4 & 4.2 & 2.4 & 2.0 \\
\hline
\end{tabular}

${ }^{\mathrm{a}}$ In msec; ${ }^{\mathrm{b}}$ total time in $\mathrm{msec} ;{ }^{\mathrm{c}}$ in $\%$.

Error Data. Only the main effect of response location approached reliability, $F(1,10)=$ $3.90, p=.077$, indicating that downward responses were less error-prone $(3.3 \%)$ than were upward responses $(7.2 \%)$. Again, the relevant Mapping $\times$ Hand interaction was far from being significant, $F<1$ (see Figure 2).

In sum, Experiment 2 revealed no Mapping $\times$ Hand interaction. This means that the $\mathrm{H}-\mathrm{V}$ effect is absent when the reference point provided by the responding hand is such as to encourage an upward-downward coding of the response direction that does not correspond to the left-right stimulus dimension. This supports the proposal that it is the reference provided by the responding hand that is critical for the $\mathrm{H}-\mathrm{V}$ effect and not the movement preference of each hand.

\section{EXPERIMENT 3}

Experiment 3 was carried out to test the referential-coding explanation of why the $\mathrm{H}-\mathrm{V}$ effect depends on the responding hand. It was assumed that in Experiment 1, because of the mirrored posture of the two hands, the upper key was coded as LEFT and the lower key as RIGHT when the left hand was used, whereas the opposite coding applied when the right hand was used. Accordingly, it should also be possible to eliminate the $\mathrm{H}-\mathrm{V}$ effect by eliminating this difference between the coding for the two hands. The simplest experimental design to test this assumption is one in which the postures of the left and the right hand-relative to the response keys-are identical rather than mirrored. To achieve this, the response board was placed either far to the left or far to the right of the subject's sagittal mid-line, so that the posture of either hand relative to the keys was similar and responding reasonably comfortable (see Figure 3 ). With the response board positioned on 

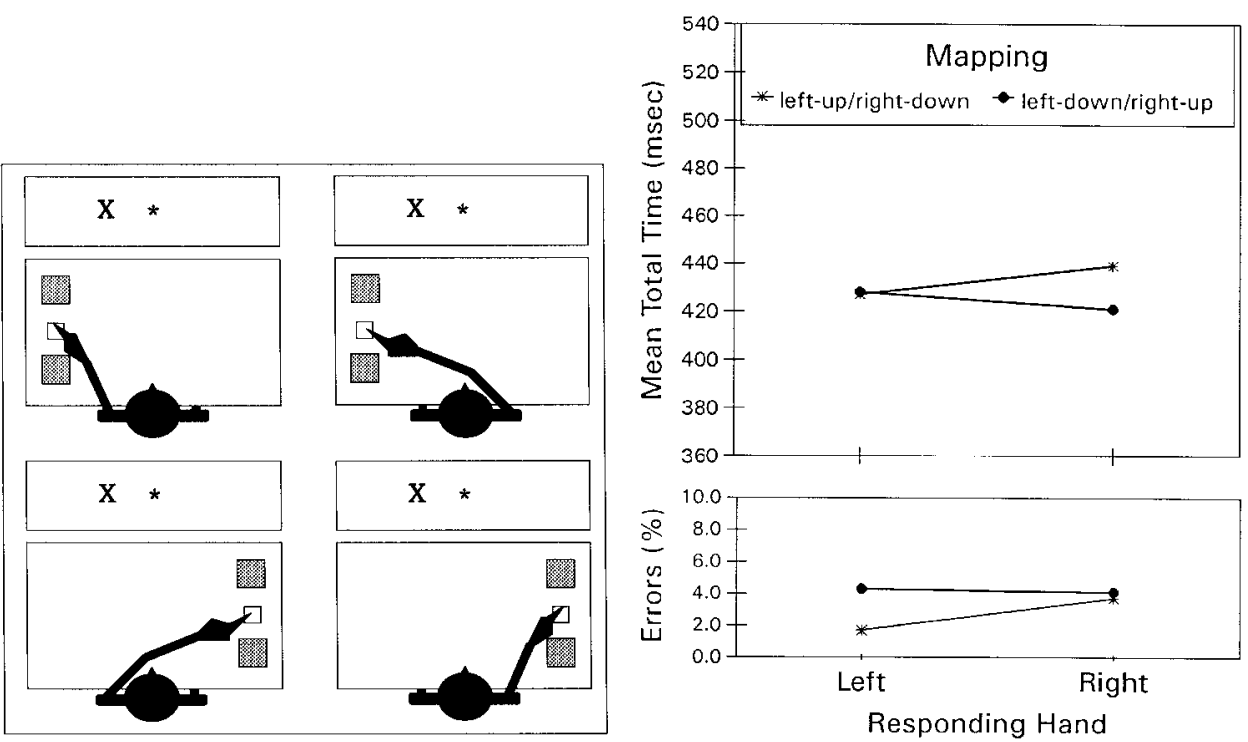

FIG. 3. Left panel: The hand posture required in Experiment 3 for left- and right-handed responses on a leftside and a right-side-located response board. Right panel: The considerably reduced $\mathrm{H}-\mathrm{V}$ effect in Experiment 3: total time and error rate as a function of mapping and responding hand.

the left, the upper key should now be coded as RIGHT and the lower key as LEFT for either hand, whereas with the response board positioned on the right, the upper key should be coded as LEFT and the lower key as RIGHT.

The referential-coding hypothesis predicts two results. First, the task should yield a SRC effect, because the posture of the hand relative to the keys causes a left-right coding of the responses, which overlaps with the coding of the stimulus dimension. Specifically, performance with the response board on the left should be better with left-down/rightup mapping than with left-up/right-down mapping, whereas performance with the response board on the right should be better with left-up/right-down mapping than with left-down/right-up mapping. Secondly, no H-V effect, or at least a considerably reduced one (i.e. a dependence of the $\mathrm{SRC}$ effect on responding hand), is predicted, because both the left and the right hand provide the same left-right reference.

The current version of the movement-preference hypothesis does not provide for an influence of response location, and the present experimental situation maintains the conditions under which movement preferences should be effective. Thus, a $\mathrm{H}-\mathrm{V}$ effect comparable to that in Experiment 1 is predicted.

\section{Method}

\section{Subjects}

Seven female and nine male subjects ( 15 right-handed and 1 ambidextrous by self-report) aged between 21 and 42 were paid to participate in the experiment. They had normal or corrected-tonormal vision. 


\section{Apparatus and Procedure}

These were identical to Experiment 1, except for the variation of response board location. The session was divided into 4 blocks of 90 trials consisting of 10 practice trials and 80 test trials (40 in each stimulus location). In two blocks, the response board was located $37 \mathrm{~cm}$ to one side, and in the other two blocks, $37 \mathrm{~cm}$ to the other side of the subject's sagittal mid-line. For both response board positions, subjects used the left index finger for one block and the right index finger for the other. The order of hands and of response board location was balanced across subjects. Subjects were instructed to hold their responding hand at a $45-90^{\circ}$ angle to the line of the response keys, particularly in the less comfortable condition, where the response hand and the board were on the same side. The subject's sagittal mid-line was in line with the fixation asterisk. Error and missing trials $(1.5 \%)$ were repeated at a random position in the block.

\section{Results}

Mean RT, MT, and error data were calculated as a function of stimulus and response location, responding hand and response board location (see Table 3). Trials with RTs less than $120 \mathrm{msec}(0.4 \%)$ were excluded from calculation. ANOVAs were conducted on the data, with the between-subject variable $\mathrm{S}-\mathrm{R}$ mapping (left-up/right-down vs. leftdown/right-up) and the within-subject variables response board location (left vs. right), response hand (left vs. right), and response location (upward vs. downward).

Total Times. The main effect of response location reached significance, $F(1,14)=$ $16.98, p<.01$, indicating that downward responses were faster $(420 \mathrm{msec})$ than upward responses (437 $\mathrm{msec})$. The Mapping $\times$ Response Board Location interaction was highly significant, $F(1,14)=134.96, p<.001$. Performance with the response board on the left was better with left-down/right-up mapping $(379 \mathrm{msec})$ than with left-up/right-down

TABLE 3

Mean $\mathrm{RT}^{\mathrm{a}}, \mathrm{MT}^{\mathrm{a}}, \mathrm{TT}^{\mathrm{b}}$, and Error Data ${ }^{\mathrm{c}}$ for Experiment 3 as a Function of Response Board Location, Responding Hand, and Stimulus and Response Location

\begin{tabular}{|c|c|c|c|c|c|c|c|c|c|}
\hline \multirow[b]{4}{*}{ Respons } & \multirow[b]{4}{*}{ Location } & \multicolumn{4}{|c|}{ Response Board on Left } & \multicolumn{4}{|c|}{ Response Board on Right } \\
\hline & & \multicolumn{2}{|c|}{ Left Hand } & \multicolumn{2}{|c|}{ Right Hand } & \multicolumn{2}{|c|}{ Left Hand } & \multicolumn{2}{|c|}{ Right Hand } \\
\hline & & \multicolumn{2}{|c|}{ Stimulus Location } & \multicolumn{2}{|c|}{ Stimulus Location } & \multicolumn{2}{|c|}{ Stimulus Location } & \multicolumn{2}{|c|}{ Stimulus Location } \\
\hline & & Left & Right & Left & Right & Left & Right & Left & Right \\
\hline \multirow[t]{4}{*}{$\mathrm{Up}$} & RT & 319 & 291 & 315 & 271 & 273 & 335 & 301 & 365 \\
\hline & MT & 158 & 120 & 135 & 94 & 119 & 126 & 136 & 140 \\
\hline & $\mathrm{TT}$ & 477 & 411 & 450 & 365 & 392 & 461 & 437 & 505 \\
\hline & Errors & 3.7 & 0.6 & 8.3 & 0.6 & 0.3 & 7.6 & 0.3 & 8.9 \\
\hline \multirow[t]{4}{*}{ Down } & RT & 266 & 327 & 271 & 332 & 339 & 269 & 344 & 289 \\
\hline & MT & 112 & 128 & 89 & 128 & 124 & 113 & 110 & 118 \\
\hline & $\mathrm{TT}$ & 378 & 455 & 360 & 460 & 463 & 382 & 454 & 407 \\
\hline & Errors & 0.3 & 2.1 & 0.6 & 5.7 & 8.8 & 0.6 & 6.3 & 0.6 \\
\hline
\end{tabular}

${ }^{\mathrm{a}}$ In msec; ${ }^{\mathrm{b}}$ total time in msec; ${ }^{\mathrm{c}}$ in $\%$. 
mapping (461 msec), whereas with the response board on the right the opposite data pattern occurred (471 vs. $405 \mathrm{msec}$ ). In addition, a Mapping $\times$ Hand interaction was found, $F(1,14)=7.75, p<.05$. As Figure 3 shows, right-hand responding was faster with left-down/right-up mapping (421 msec) than with left-up/right-down mapping (439 $\mathrm{msec})$, whereas for left-hand responding no difference occurred (428 vs. $427 \mathrm{msec})$.

Moreover, there was a main effect of response board location, $F(1,14)=7.99, p<.05$, which was modified by a higher-order Response Board Location $\times$ Hand interaction, $F(1,14)=9.42, p<.01$, and, additionally, by a higher-order Response Board Location $\times$ Hand $\times$ Response interaction, $F(1,14)=59.90, p<.001$. For upward responses, both the left and the right hand showed a reaction time disadvantage for responses on the response board located on the same side (444 and $471 \mathrm{msec}$ for left and right hand, respectively) and an advantage for responses on the response board located on the opposite side (427 and $408 \mathrm{msec})$. For downward responses, this influence of a comfortable and less comfortable response board location was only partially effective. Right-hand performance was better with the response board on the left than on the right (410 vs. $431 \mathrm{msec})$, but left-hand performance was scarcely affected by board location (417 vs. $423 \mathrm{msec}$ ).

As an additional check for the significance of the present Mapping $\times$ Hand interaction, an ANOVA was conducted on the data of Experiment 1 and Experiment 3, with experiment as an additional variable. As expected, a significant Experiment $\times$ Mapping $\times$ Hand interaction was revealed, $F(1,28)=10.00, p<.01$, indicating that the size of the present $\mathrm{H}-\mathrm{V}$ effect $(10 \mathrm{msec})$ was considerably smaller than that of the $\mathrm{H}-\mathrm{V}$ effect obtained in Experiment 1 (45 $\mathrm{msec})$.

$R T$ and MT Data. The Mapping $\times$ Response Board Location interaction was reliable in both RT, $F(1,14)=53.51, p<.001$, and MT data, $F(1,14)=16.58, p<$ .01 . In contrast, the $M$ apping $\times$ Hand interaction failed to reach significance in $\mathrm{RT}$ data, $F(1,14)=1.36, p=.262$, and occurred only in MT data, $F(1,14)=8.74, p<.05$, modified by a higher-order Mapping $\times$ Hand $\times$ Response interaction, $F(1,14)=4.64$, $p<.05$; the $\mathrm{H}-\mathrm{V}$ effect was present with downward, but not with upward movements.

Error Data. The main effect of mapping, $F(1,14)=5.97, p<.05$, of response board location, $F(1,14)=5.84, p<.05$, and the interaction between these factors, $F(1,14)=$ $97.15, p<.001$, reached significance. With the response board on the left, fewer errors were made with the left-down/right-up mapping $(0.5 \%)$ than with the left-up/rightdown mapping $(5.0 \%)$, whereas responding with the response board on the right reversed the effects $(7.9$ vs. $0.5 \%)$. In addition, the Mapping $\times$ Hand interaction approached reliability, $F(1,14)=4.40, p=.055$ (see Figure 3 ). Left-hand performance was less errorprone with the left-up/right-down mapping $(1.7 \%)$ than with the left-down/right-up mapping $(4.3 \%)$, but right-hand performance remained unaffected (3.7 vs. $4.1 \%)$. Finally, a Response Board Location $\times$ Hand interaction reached significance, $F(1,14)=$ $4.71, p<.05$. For left-hand responses, there were fewer errors with the response board on the left than on the right $(1.7$ vs. $4.3 \%)$, whereas for right-hand responses, the same number of errors were made (3.8 vs. $4.0 \%)$. 


\section{Discussion}

There are two main results: First of all, a Mapping $\times$ Response Board Location interaction was found. Responding with the response board on the left was faster and less error-prone with the left-down/right-up mapping than with the left-up/right-down mapping, whereas the opposite data pattern occurred with the response board on the right. The second main result concerns the Mapping $\times$ Hand interaction obtained. Actually, the data pattern corresponds to the $\mathrm{H}-\mathrm{V}$ effect, but its size shows a statistically significant decrease from $45 \mathrm{msec}$ in Experiment 1 to $10 \mathrm{msec}$. Moreover, there is reason to query the reliability of this $\mathrm{H}-\mathrm{V}$-like pattern: It was obtained only in M T data and with downward movements only. Hence, it should be cautiously interpreted.

Thus, Experiment 3 yielded a SRC effect dependent on response board location and a considerably reduced $\mathrm{H}-\mathrm{V}$ effect. Both results again support the proposal that it is the reference provided by the responding hand and not the movement preference of each hand that is critical for the $\mathrm{H}-\mathrm{V}$ effect.

Up to now, the referential-coding idea has correctly predicted the conditions for the presence and the absence of the $\mathrm{H}-\mathrm{V}$ effect as well as the dependence of the SRC effect on response board location. In contrast, the movement-preference hypothesis cannot readily account for these results, as, in its current version, it is unclear why eccentricity of response location or hand posture should modulate the $\mathrm{H}-\mathrm{V}$ and SRC effects. However, Bauer and Miller (1982, Exp. 3) offered further evidence for their movement-preference idea. They predicted another SRC effect dependent on the response hand by examining vertically oriented stimuli and horizontally oriented responses. This $V-H$ effect is discussed in the next section.

\section{THE V-H EFFECT}

In Bauer and Miller's third experiment, subjects had to press a left or right key with one index finger in response to a stimulus appearing above or below a fixation point. Again, they predicted that left-hand performance would be better with clockwise movements and that right-hand performance would be better with counterclockwise movements. Note that in this design clockwise movements are caused by up-right/down-left mapping, whereas counterclockwise movements are caused by up-left/down-right mapping. Bauer and Miller indeed yielded a Mapping $\times$ Hand interaction, but, again, there was no crossover interaction because, this time, right-handed responding was faster overall. That is, a $\mathrm{V}-\mathrm{H}$ effect occurred in that the advantage of up-right/down-left mapping was greater for the left $(65 \mathrm{msec})$ than for the right $(20 \mathrm{msec})$ hand.

There have been several attem pts to replicate the $\mathrm{V}-\mathrm{H}$ effect, but its reliability seems to be questionable: Some studies have obtained a Mapping $\times$ Hand interaction (Michaels, 1989, Exp. 1; Michaels \& Schilder, 1991, Exp. 3, prone position), but others have not (Michaels \& Schilder, 1991, Exp. 1, midline position; Weeks \& Proctor, 1990, Exp. 1).

The referential-coding idea casts light on this rather confusing data pattern because, depending on the particular hand posture, both the presence and the absence of the $\mathrm{V}-\mathrm{H}$ effect can be predicted. The $\mathrm{V}-\mathrm{H}$ effect should be present if the responding hand is in line with the response keys, as shown in Figure 4. Under these conditions, responses should be coded not as "left" and "right", but as "upward" and "downward". As the vertical 

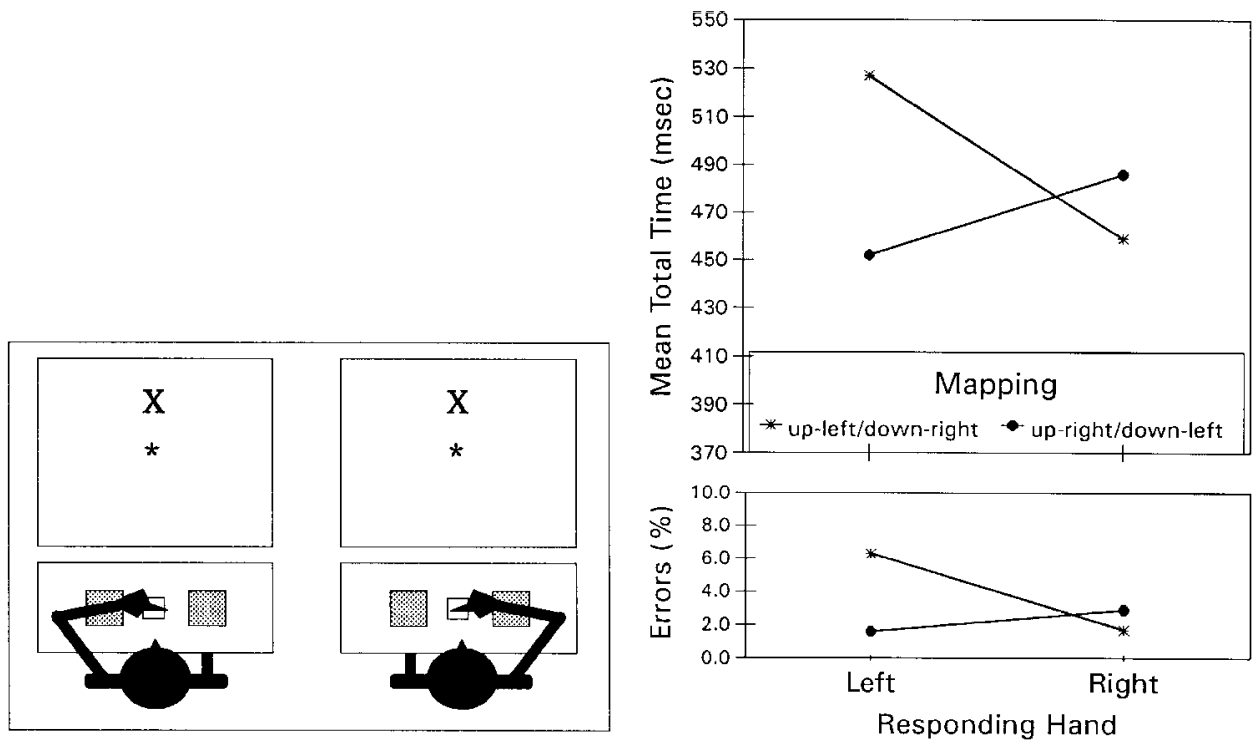

FIG. 4. Left panel: The hand posture required in Experiment 4 for left- and right-handed responses. Right panel: the $\mathrm{V}-\mathrm{H}$ effect in Experiment 4: total time and error rate as a function of mapping and responding hand.

response dimension then overlaps with the vertical stimulus dimension and the coding of a physically left or right key as TOP or воттом depends on the responding hand, a $\mathrm{V}-\mathrm{H}$ effect is expected in this situation. In contrast, the referential-coding hypothesis predicts the absence of or at least a considerably reduced $\mathrm{V}-\mathrm{H}$ effect if the responding hand is positioned at a $90^{\circ}$ angle to the line of the response keys (as in Figure 5). In this case, the left key is to the left and the right key to the right side of the responding hand, so that the response positions should be coded orthogonally to those of the vertical stimulus set. In this situation, SRC effects dependent on hand should be absent or small. In order to test the referential-coding explanations for the presence and absence of the $\mathrm{V}-\mathrm{H}$ effect, Experiments 4 and 5 were carried out.

\section{EXPERIMENT 4}

Experiment 4 was designed to create a situation in which the referential-coding hypothesis predicts a $\mathrm{V}-\mathrm{H}$ effect. The subjects' task was to respond to top and bottom stimuli by touching a left or right response key unimanually. In addition, they were explicitly instructed to keep their responding hand in line with the keys (see Figure 4). This situation should cause the physically left and right response keys to be coded as TOP and воттом, depending on the responding hand. Therefore, the referential-coding hypothesis predicts, for the left hand, better performance with up-right/down-left mapping than with up-left/down-right mapping, whereas for the right hand the opposite data pattern is predicted. 


\section{Method}

\section{Subjects}

Ten female and two male subjects aged between 19 and 33 were paid for their participation. All claimed to be right-handed, and all had normal or corrected-to-normal vision.

\section{Apparatus and Procedure}

These were as in Experiment 1, with the following exceptions. First, the experiment was controlled by a Mega/STE computer. Second, in addition to error and $\mathrm{missing}$ trials $(0.7 \%)$, trials with RTs less than $120 \mathrm{msec}(0.2 \%)$ were repeated at a random position in the block. Third, the reversed $\mathrm{S}-\mathrm{R}$ set was used: Stimuli appeared $1.6 \mathrm{~cm}$ above or below the fixation asterisk, and the response board was turned through $90^{\circ}$ so that the response keys were oriented horizontally. One half of the subjects touched the left and the right key in response to top or bottom stimuli, respectively, whereas the other half used the reversed mapping. In addition, they were required to hold their responding hand in line with the response keys throughout. The subject's sagittal mid-line was in line with the home key and the fixation asterisk.

\section{Results and Discussion}

RT, MT, and error data were treated as in Experiment 1, and their means are presented in Table 4. ANOVAs were conducted on the data, with the between-subject variable $S-R$ mapping (up-left/down-right vs. up-right/down-left) and the within-subject variables response hand (left vs. right) and response location (left vs. right).

Total Times. A Mapping $\times$ Hand interaction did occur, $F(1,10)=11.02, p<.01$. As Figure 4 shows, left-hand responding was faster with up-right/down-left mapping (452 msec) than with up-left/down-right mapping (527 $\mathrm{msec})$, whereas right-hand

TABLE 4

Mean $\mathrm{RT}^{\mathrm{a}}, \mathrm{MT}^{\mathrm{a}}, \mathrm{TT}^{\mathrm{b}}$, and Error Data ${ }^{\mathrm{c}}$ for Experiment 4 as a Function of Responding Hand and Stimulus and Response Location

\begin{tabular}{|c|c|c|c|c|c|}
\hline \multirow{3}{*}{\multicolumn{2}{|c|}{ Response Location }} & \multirow{2}{*}{\multicolumn{2}{|c|}{$\frac{\text { Left Hand }}{\text { Stimulus Location }}$}} & \multirow{2}{*}{\multicolumn{2}{|c|}{$\frac{\text { Right Hand }}{\text { Stimulus Location }}$}} \\
\hline & & & & & \\
\hline & & \multirow{2}{*}{$\begin{array}{c}U p \\
399\end{array}$} & \multirow{2}{*}{$\frac{\text { Down }}{349}$} & \multirow{2}{*}{$\frac{U p}{339}$} & \multirow{2}{*}{$\frac{\text { Down }}{384}$} \\
\hline Left & RT & & & & \\
\hline & $\mathrm{MT}$ & 111 & 85 & 138 & 127 \\
\hline & TT & 510 & 434 & 477 & 511 \\
\hline & Errors & 6.1 & 1.6 & 3.0 & 4.5 \\
\hline \multirow[t]{4}{*}{ Right } & RT & 345 & 403 & 381 & 333 \\
\hline & $\mathrm{MT}$ & 125 & 141 & 80 & 107 \\
\hline & $\mathrm{TT}$ & 470 & 544 & 461 & 440 \\
\hline & Errors & 1.6 & 6.5 & 1.2 & 0.4 \\
\hline
\end{tabular}

${ }^{\mathrm{a}}$ In msec; ${ }^{\mathrm{b}}$ total time in $\mathrm{msec} ;{ }^{\mathrm{c}}$ in $\%$. 
responding was faster with up-left/down-right mapping (459 $\mathrm{msec})$ than with upright/down-left mapping (486 $\mathrm{msec})$. In addition, the Hand $\times$ Response Location interaction reached significance, $F(1,10)=41.84, p<.001$, indicating that a correspondence between hand and response location, such as the left hand making a leftward response, yielded better performance than non-correspondence, such as the left hand making a rightward response.

Error Data. The main effect of hand approached reliability, $F(1,10)=4.83, p=.053$, and was modified by the higher-order Mapping $\times$ Hand interaction, $F(1,10)=14.99$, $p<.01$ (see Figure 4). A test of simple main effects shows that left-hand performance was less error-prone with up-right/down-left mapping $(1.6 \%)$ than with up-left/down-right mapping $(6.3 \%), F(1,10)=4.83, p=.053$, whereas right-hand performance was not significantly affected $(2.9$ vs. $1.7 \%), F<1$.

In sum, a $\mathrm{V}-\mathrm{H}$ effect occurred when the responding hand was situated in line with the response keys. This is consistent with the assumption that SRC effects dependent on hand arise when hand posture causes a response coding overlapping with the stimulus dimension. In addition, it suggests that some previous studies may have failed to find a $\mathrm{V}-$ $\mathrm{H}$ effect because hand posture was not properly controlled.

\section{EXPERIMENT 5}

Experiment 5 examined a situation in which referential-coding predicts a small or absent $\mathrm{V}-\mathrm{H}$ effect. It was identical to Experiment 4, with the exception that subjects were explicitly instructed to hold their responding hand at a right angle to the line of the response keys throughout (see Figure 5). Regardless of the response hand, this situation should cause a left-right coding of the response set that is orthogonal to the top-bottom coding of the stimulus set, and, thus, a $\mathrm{V}-\mathrm{H}$ effect is not expected.

\section{Method}

\section{Subjects, Apparatus, and Procedure}

Eight female and eight male subjects aged between 19 and 39 were paid for their participation. All claimed to be right-handed and all had normal or corrected-to-normal vision. The apparatus and the procedure were the same as in Experiment 4, but the subjects were required to keep their responding hand at a right angle to the line of the response keys. To avoid uncomfortable hand postures, subjects were allowed to sit approximately $1 \mathrm{~m}$ away from the screen. The subject's sagittal mid-line and the hand were then in line with the home key and fixation asterisk. Error and missing trials $(0.4 \%)$ as well as trials with RTs less than $120 \mathrm{msec}(0.0 \%)$ were repeated at a random position in the block.

\section{Results}

RT, M T, and error data were treated and analysed as in Experiment 4, and their means are presented in Table 5 .

Total Times. The main effect of mapping reached significance, $F(1,14)=9.88, p<.01$. With up-right/down-left mapping, performance was better (386 m sec) than with up-left/ down-right mapping $(440 \mathrm{msec})$. In addition, the Hand $\times$ Response Location interaction 

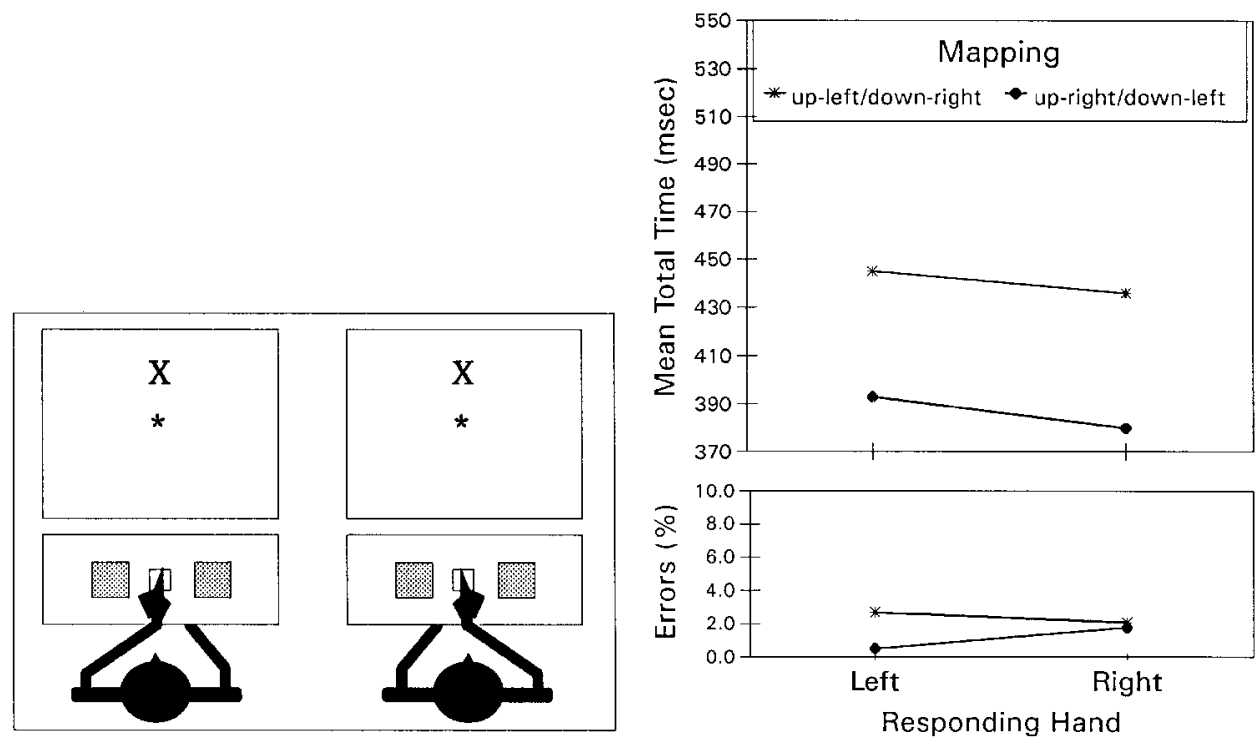

FIG. 5. Left panel: The hand posture required in Experiment 5 for left- and right-handed responses. Right panel: The absence of the $\mathrm{V}-\mathrm{H}$ effect in Experiment 5: total time and error rate as a function of mapping and responding hand.

was significant, $F(1,14)=10.27, p<.01$, indicating that right-hand responses were faster for rightward than for leftward responses, whereas left-hand responses, did not differ. The relevant $M$ apping $\times$ Hand interaction was far from being significant, $F<1$ (see Figure 5).

As an additional check for the disappearance of the Mapping $\times$ Hand interaction, an ANOVA was conducted on the data of Experiment 4 and Experiment 5 with experiment as an additional variable. As expected, a significant Experiment $\times$ Mapping $\times$ Hand interaction was revealed, $F(1,24)=12.59, p<.01$, indicating that the $\mathrm{V}-\mathrm{H}$ effect was present in Experiment 4 but not in Experiment 5 .

$R T$ and $M T$ Data. Whereas in RT data no Mapping $\times$ Hand interaction occurred, $F<1$, MT data revealed a Mapping $\times$ Hand $\times$ Response Location interaction, $F(1,14)=$ $7.15, p<.05$, indicating a reversed $\mathrm{V}-\mathrm{H}$ effect for leftward responses only. Left-handed responses to the left had shorter movement times in response to top than to bottom stimuli (114 vs. $128 \mathrm{msec}$ ), whereas right-handed responses to the left were scarcely affected by the stimulus position (121 vs. $115 \mathrm{msec}$ ).

Error Data. As Figure 5 shows, error data suggested an advantage of the up-right/ down-left mapping for the left hand, but this Mapping $\times$ Hand interaction was only marginally significant, $F(1,14)=3.15, p=.097$. 
TABLE 5

Mean $\mathrm{RT}^{\mathrm{a}}, \mathrm{MT}^{\mathrm{a}}, \mathrm{TT}^{\mathrm{b}}$, and Error Data ${ }^{\mathrm{c}}$ for Experiment 5 as a Function of Responding Hand and Stimulus and Response Location

\begin{tabular}{|c|c|c|c|c|c|}
\hline \multirow{3}{*}{\multicolumn{2}{|c|}{ Response Location }} & \multirow{2}{*}{\multicolumn{2}{|c|}{$\frac{\text { Left Hand }}{\text { Stimulus Location }}$}} & \multirow{2}{*}{\multicolumn{2}{|c|}{$\frac{\text { Right Hand }}{\text { Stimulus Location }}$}} \\
\hline & & & & & \\
\hline & & \multirow{2}{*}{$\frac{U p}{325}$} & \multirow{2}{*}{$\frac{\text { Down }}{265}$} & \multirow{2}{*}{$\frac{U p}{323}$} & \multirow{2}{*}{$\frac{\text { Down }}{273}$} \\
\hline Left & RT & & & & \\
\hline & $\mathrm{MT}$ & 114 & 128 & 121 & 115 \\
\hline & $\mathrm{TT}$ & 439 & 393 & 444 & 388 \\
\hline & Errors & 2.1 & 0.6 & 2.4 & 1.9 \\
\hline \multirow[t]{4}{*}{ Right } & RT & 268 & 324 & 266 & 318 \\
\hline & $\mathrm{MT}$ & 125 & 127 & 105 & 109 \\
\hline & $\mathrm{TT}$ & 393 & 451 & 371 & 427 \\
\hline & Errors & 0.4 & 3.2 & 1.6 & 1.8 \\
\hline
\end{tabular}

${ }^{\mathrm{a}}$ In msec; ${ }^{\mathrm{b}_{\text {Total }}}$ time in $\mathrm{msec} ;{ }^{\mathrm{c}}$ in $\%$.

\section{Discussion}

As predicted by the referential-coding hypothesis, the $\mathrm{V}-\mathrm{H}$ effect disappeared when the responding hand was situated at a right angle to the line of the response keys, so that the response positions would be coded orthogonally to the stimulus positions. This condition was even better met by Michaels and Schilder's first experiment (1991, midline position). They used a response apparatus that locked the responding hand in front of the body, so that only left-right movements perpendicular to the fingertip-to-wrist axis could be performed. Under this experimental condition, the $\mathrm{V}-\mathrm{H}$ effect disappeared completely. Therefore, it can be concluded that the absence of the $\mathrm{V}-\mathrm{H}$ effect results from the response hand being situated at a right angle to the line of the response keys or, more generally, from the left-right coding of the response set.

There is no ready explanation for why $\mathrm{MT}$ data revealed a reversed $\mathrm{V}-\mathrm{H}$ effect for leftward responses. Neither the movement-preference hypothesis, which would have predicted a positive $\mathrm{V}-\mathrm{H}$ effect, nor the referential-coding hypothesis, which predicted no SRC effects at all, come up with a reasonable account for this particular finding.

In conditions that eliminated the $\mathrm{V}-\mathrm{H}$ effect, another compatibility effect occurred, namely a significant overall superiority of the up-right/down-left mapping to the upleft/down-right mapping. Such an effect was first reported by Weeks and Proctor (1990) and is beyond the scope of the referential-coding hypothesis, because, for the $\mathrm{V}-\mathrm{H}$ design, this predicts either the presence of a $\mathrm{V}-\mathrm{H}$ effect or no SRC effect at all. I will refer to this point later on.

\section{GENERAL DISCUSSION}

The present study has addressed the dependence of SRC effects on responding hand with horizontally oriented stimuli and vertically oriented responses ( $\mathrm{H}-\mathrm{V}$ effect) and with vertically oriented stimuli and horizontally oriented responses ( $\mathrm{V}-\mathrm{H}$ effect) reported by 
Bauer and Miller (1982). The first three experiments focused on the H-V effect. Experiment 1 replicated the $\mathrm{H}-\mathrm{V}$ effect. In Experiment 2, the basic $\mathrm{H}-\mathrm{V}$ design was maintained, but subjects were instructed to respond with their hands in line with the response keys. This eliminated the $\mathrm{H}-\mathrm{V}$ effect. In Experiment 3, the response board was placed to the left or right side of the subject. This yielded a considerably reduced $\mathrm{H}-\mathrm{V}$ effect as well as a novel SRC effect dependent on response board location. Experiment 4 and 5 focused on the $\mathrm{V}-\mathrm{H}$ effect. In Experiment 4, this effect was produced when subjects were required to position the responding hand in line with the response keys. With the hand rotated through $90^{\circ}$ in Experiment 5, the $\mathrm{V}-\mathrm{H}$ effect was eliminated and a significant superiority of up-right/down-left mapping compared to up-left/down-right mapping was observed.

The present evidence provides ample support for the referential-coding hypothesis, favouring it over Bauer and Miller's movement-preference hypothesis. First of all, the explanatory scope of the referential-coding hypothesis is broader than that of the movement-preference hypothesis. Whereas the latter accounts only for the presence of the $\mathrm{H}-$ $\mathrm{V}$ and $\mathrm{V}-\mathrm{H}$ effect, the referential-coding hypothesis also predicts the conditions that eliminate both effects and those that produce the SRC effect dependent on response board location. Of course, it might be possible to come up with a modified movementpreference hypothesis that accounted for the entire range of the present results by introducing assumptions about posture-dependent movement preferences. But these would be unsatisfactorily post hoc and certainly less parsimonious than the referentialcoding hypothesis, which gets by on a single assumption. In fact, the present experiments have examined only some of the possible applications of the referential-coding logic: If hand posture causes a response coding that overlaps with the stimulus dimension, SRC effects dependent on hand should occur; and if hand posture causes a response coding that does not overlap with the stimulus set, no SRC effects dependent on hand should be found.

Within the paradigm of physically orthogonal $S-R$ dimensions, the present study is the first to test the referential-coding account systematically. However, other authors have previously considered the idea to explain their effects, but rejected it in favour of more complex explanations (Cotton et al., 1977; Ehrenstein et al., 1989). To what extent these are needed or how far the referential-coding idea is applicable to other SRC effects of physically orthogonal $\mathrm{S}-\mathrm{R}$ sets is discussed in the next section.

\section{The Explanatory Scope of the Referential-coding Hypothesis}

First of all, let us focus on some findings from $\mathrm{H}-\mathrm{V}$-like designs. To the best of my knowledge, there are only three relevant experiments, and they all produced results consistent with the referential-coding hypothesis. Michaels (1989, Exp. 2) asked her subjects to deflect a toggle switch, located on a horizontal table, upwards (i.e. away from the subject's body) or downwards in response to left and right stimuli. In a midline condition, the toggle switch was located in front of the subjects; in eccentric conditions, it was located $60 \mathrm{~cm}$ to the left or the right of the subject's sagittal midline. In the midline condition, subjects were instructed to hold the switch with the index finger on the top and the thumb on the bottom; in the eccentric conditions, the thumb was on the top and the index finger on the bottom. In the midline condition a $\mathrm{H}-\mathrm{V}$ effect was observed, but in the 
eccentric conditions there was a reversed $\mathrm{H}-\mathrm{V}$ effect - that is, a left-hand advantage with left-down/right-up mapping and a right-hand advantage with left-up/right-down mapping. In principle, this experimental design combines the conditions of Experiments 1 and 3 of the present study. Therefore, the referential-coding explanation is the same: Given the instructed hand postures, it can be assumed that in both midline and eccentric conditions, the up- and downward deflections were coded as left and right with respect to the fingertip-to-wrist axis. As the reference provided by the left and right hand in the eccentric conditions was opposite to that in the midline conditions, the $\mathrm{H}-\mathrm{V}$ effect at midline position should be reversed at eccentric positions.

Ehrenstein et al. (1989) investigated SRC effects of physically orthogonal S-R dimensions with unimanual two-finger choice reactions in a Simon task. Two conditions of their experiment were similar to the experimental design used here. Subjects responded to red and green lights appearing in the left or right visual field by pressing vertically oriented response keys with the index and middle finger of the left or right hand. In one condition, the subjects' palms faced down; in the other, the palms faced up. Ehrenstein et al. expected that SRC effects would depend on the anatomical left- and rightness of the index and middle finger, so that with palms up SRC effects opposite to those with palms down were predicted. Instead, for both conditions, SRC effects referring to the response position were obtained: Left-hand performance was best for left-up/right-down trials, whereas right-hand performance was best for left-down/right-up trials. According to the referential-coding hypothesis, this data pattern is expected if it is assumed that the hand reference axis reverses with responding hand, but not with supine or prone position ${ }^{2}$.

Cotton et al. (1977, Exp. 2; 1980, Exp. 1) used the same design as in the present Experiment 1, except for the stimulus array. The stimuli presented varied not only on the horizontal but also on the vertical dimension, so that left and right stimuli appeared either above or below a central fixation point. Subjects were instructed to respond to top stimuli with the upper key and to bottom stimuli with the lower key, independent of whether they were left or right of the fixation point. The results revealed that left-hand responding was faster when top stimuli appeared on the left and bottom stimuli on the right side, whereas right-hand responding was faster when top stimuli appeared on the right and bottom stimuli on the left side. In the light of the referential-coding hypothesis, the influence of the irrelevant horizontal stimulus dimension is at least reasonable. Though Cotton et al. do not report hand posture in detail, one may speculate that the responding hands were situated at a $45-90^{\circ}$ angle to the line of the response keys, so that the upper and lower response keys were coded as left and right, too. Therefore, both stimuli and responses varied horizontally and vertically, which permits a $\mathrm{H}-\mathrm{V}$ effect for both dimensions.

Studies using $\mathrm{V}-\mathrm{H}$-like designs have largely investigated the influence of response eccentricity and revealed that the $\mathrm{V}-\mathrm{H}$ effect obtained in midline position reverses with

${ }^{2}$ For left-hand responding Michaels and Schilder (1991, Exp. 3) found an advantage of up-right/down-left mapping with the palm facing down and an advantage of up-left/down-right mapping with the palm facing up, hence different SRC effects for prone and supine postures. Unfortunately, Michaels and Schilder do not report whether the prone vs. supine posture manipulation also produced a change of the intrinsic fingertip-to-wrist axis relative to the response position (left-right deflections of a toggle switch) and whether the hand axis was controlled at all. So, their failure to replicate Ehrenstein et al.'s (1989) results might be due to intra- and/or in terindividually varying hand postures. 
increasing eccentricity (Michaels, 1989, Exp. 1; Michaels \& Schilder, 1991, Exp. 1; Weeks, Proctor \& Beyak, 1995). That is, with a response panel located on the subject's left or right side, left-hand performance was better with up-left/down-right mapping and righthand performance was better with up-right/down-left mapping. With respect to the experiments carried out with toggle switches, one could argue that increasing eccentricity changed hand posture so that it was not left-right but upward and downward deflections that were performed. If so, there was once again a dimensional overlap with the stimulus set, which permitted SRC effects. Thus, it was not the eccentricity of response location per se, but the resulting hand posture that was responsible for the reversal. Although this explanation is probably valid for some of the results, it is not complete. Michaels and Schilder (1991, Exp. 1) showed that the reversal of the V-H effect at eccentric positions also occurs if the hand is locked such that only left-right deflections are permitted. As the hand-related coding of the response set should be orthogonal to the top-bottom stimulus dimension, the referential-coding hypothesis would predict no SRC effects at all.

Actually, the explanatory scope of the present referential-coding hypothesis ends here. As it postulates an influence of hand posture only, its predictive power is limited. Nevertheless, the basic idea behind the referential-coding hypothesis-namely, that actions are coded with respect to frames of reference-is more generally applicable. For instance, it is possible that in the tasks described above, responses were coded with respect to the body. If so, left-right deflections, as responses away from and towards the body, may have been coded as upwards and downwards, which would again result in a dimensional overlap with the stimulus dimension.

To sum up, the present version of the referential-coding hypothesis accounts for a range of findings obtained within $\mathrm{H}-\mathrm{V}$-like and $\mathrm{V}-\mathrm{H}$-like designs. Moreover, generalizing from the present referential-coding hypothesis to some other frames of reference might help to explain other known effects and probably also to predict novel SRC effects.

\section{The Significance of the Referential-coding Idea for Theories of S-R Compatibility}

In general, the referential-coding hypothesis can be regarded as a missing link that bridges the gap between SRC theories that rely on the dimensional overlap assumption and compatibility effects observed with $S-R$ sets that do not seem to fulfil this criterion. With the referential-coding hypothesis, most of the effects of physically orthogonal $\mathrm{S}-\mathrm{R}$ dimensions can be shown to depend on coding in a spatial dimension common to stimulus and response representations and are thus open to explanation by conventional SRC theories.

However, there are still some SRC effects that cannot be accommodated to conventional SRC theories by the referential-coding hypothesis-for example, the overall superiority of up-right/down-left mapping to up-left/down-right mapping obtained in Experiment 5 . According to the referential-coding hypothesis, this mapping effect occurs with orthogonally coded $\mathrm{S}-\mathrm{R}$ dimensions, as the hand-related coding of the response set did not overlap with the coded stimulus set. This effect requires another explanation such as the salientfeatures coding principle proposed by Weeks and colleagues (Weeks \& Proctor, 1990; Weeks et al., 1995). This "attributes the preference for the up-right/down-left mapping to the correspondence between the salient polar referents of the stimulus and response 
dimensions (up and right, respectively) that it instantiates" (Weeks et al., 1995, p. 380). That is, up-right/down-left mapping is preferred, because the salient features of the $S-R$ set match. Hence, like the referential coding hypothesis, the salient features coding principle also tries to solve the problem of orthogonal stimulus and response dimensions by proposing a form of cognitive overlap between them. By combining these hypotheses, it may be possible to interpret all effects of compatibility between physically orthogonal stimulus and response dimensions within the same framework as the classic SRC effects.

\section{REFERENCES}

Bauer, D.W., \& Miller, J. (1982). Stimulus-response compatibility and the motor system. The Quarterly Journal of Experimental Psychology, 34A, 367-380.

Carpenter, P.A., \& Eisenberg, P. (1978). Mental rotation and the frame of reference in blind and sighted individuals. Perception \& Psychophysics, 23, 117-124.

Cotton, B., Tzeng, O.J.L., \& Hardyck, C. (1977). A response instruction by visual-field interaction: S-R compatibility effect or? Bulletin of the Psychonomic Society, 10, 475-477.

Cotton, B., Tzeng, O.J.L., \& Hardyck, C. (1980). Role of cerebral hemispheric processing in the visual half-field stimulus-response compatibility effect. Journal of Experimental Psychology: Human Perception and Performance, 6, 13-23.

De Jong, R., Liang, Ch.Ch., \& Lauber, E. (1994). Conditional and unconditional automaticity: A dualprocess model of effects of spatial stimulus-response correspondence. Journal of Experimental Psychology: Human Perception and Performance, 20, 731-750.

Ehrenstein, W.H., Schroeder-Heister, P., \& Heister, G. (1989). Spatial S-R compatibility with orthogonal stimulus-response relationship. Perception \& Psychophysics, 45, 215-220.

Fitts, P.M., \& Seeger, C.M. (1953). S-R compatibility: Spatial characteristics of stimulus and response codes. Journal of Experimental Psychology, 46, 199-210.

Hasbroucq, Th., Guiard, Y., \& Ottomani, L. (1990). Principles of response determination: The list-rule model of SR compatibility. Bulletin of the Psychonomic Society, 28, 327-330.

Kornblum, S., Hasbroucq, T., \& Osman, A. (1990). Dimensional overlap: Cognitive basis for stimulusresponse compatibility-A model and taxonomy. Psychological Review, 97, 253-270.

Làdavas, E. (1987). Influence of handedness on spatial compatibility effects with perpendicular ar rangement of stimuli and responses. Acta Psychologica, 64, 13-23.

Làdavas, E., \& Moscovitch, M. (1984). Must egocentric and environmental frames of reference be aligned to produce spatial S-R compatibility effects? Journal of Experimental Psychology: Human Perception and Performance, 10, 205-215.

Michaels, C.F. (1989). S-R compatibilities depend on eccentricity of responding hand. The Quarterly Journal of Experimental Psychology, 41A, 263-272.

Michaels, C.F., \& Schilder, S. (1991). Stimulus-response compatibilities between vertically oriented stimuli and horizontally oriented responses: The effects of hand position and posture. Perception \& Psychophysics, 49, 342-348.

Simon, J.R. (1969). Reactions toward the source of stimulation. Journal of Experimental Psychology, 81, $174-176$.

Umiltà, C., \& Nicoletti, R. (1992). An integrated model of the Simon effect. In J. Alegria, D. Holender, J. Junca de Morais, \& M. Radeau (Eds.), Analytic approaches to human cognition (pp. 331-350). Amsterdam: Elsevier.

Weeks, D.J., \& Proctor, R.W. (1990). Salient-features coding in the translation between orthogonal stimulus and response dimensions. Journal of Experimental Psychology: General, 119, 355-366.

Weeks, D.J., Proctor, R.W., \& Beyak, B. (1995). Stimulus-response compatibility for vertically oriented stimuli and horizontally oriented responses: Evidence for spatial coding. The Quarterly Journal of Experimental Psychology, 48A, 367-383.

Welford, A.T. (1976). Skilled performance: Perceptual and motor skills. Glenview, IL: Scott, Foresman. 
Copyright of Quarterly Journal of Experimental Psychology: Section A is the property of Psychology Press (T\&F) and its content may not be copied or emailed to multiple sites or posted to a listserv without the copyright holder's express written permission. However, users may print, download, or email articles for individual use. 